\title{
PRAKSA KLAVIRSKEGA IMPROVIZIRANJA NA PRIMERU CZERNYJEVE RAZPRAVE. SYSTEMATISCHE ANLEITUNG ZUM FANTASIEREN AUF DEM PIANOFORTE
}

\author{
ANA VONČINA
}

Izvleček: Na temelju analize Czernyjeve razprave Systematische Anleitung zum Fantasieren auf dem Pianoforte članek opisuje prakso klavirskega improviziranja $v$ 19. stoletju in podaja vpogled $v$ veščine in vrednote profesionalnih pianistov tistega časa. Analiza razkriva, da so bile za klavirskega improvizatorja 19. stoletja najpomembnejše naslednje lastnosti: tehnična izurjenost in virtuoznost, sposobnost oblikovanja improvizacij v skladu s kompozicijsko tradicijo ter družbena inteligenca, potrebna za sporazumevanje in povezovanje s publiko.

Ključne besede: zgodovina improvizacije, klavirska improvizacija 19. stoletja, Carl Czerny, estetika improviziranja

\begin{abstract}
Proceeding from the analysis of Czerny's treatise Systematische Anleitung zum Fantasieren auf dem Pianoforte, the article describes the practice of keyboard improvisation in the $19^{\text {th }}$ century and offers an insight into the values and skills of professional pianists of that time. The analysis reveales that the most important aspects of the $19^{\text {th }}$-century piano improvisation were technical proficiency and virtuosity, the ability to create improvisations in accordance with the compositional tradition, and social intelligence, needed in order to enable the communication and contact with the audience.
\end{abstract}

Keywords: history of improvisation, nineteenth-century keyboard improvisation, Carl Czerny, aestetics of improvisation

\section{Uvod}

Improvizacijski praksi je mogoče slediti od srednjeveškega organuma pa vse do sredine 19. stoletja, ko je za nekaj časa poniknila. Spretnost improviziranja je v vseh zgodovinskih obdobjih predstavljala pomembno glasbeno veščino. Različne improvizacijske tradicije v zgodovini zahodnoevropske glasbe so omogočale več ali manj improvizacijske svobode. Ernst Ferand, avtor prvega antološkega pregleda o zgodovini improvizacije $(1938)^{1}$ in eden prvih muzikologov, ki je opozoril na pomen improvizacije v zahodnoevropski glasbi, je menil, da je mogoče ločevati med absolutno in relativno, svobodno in zamejeno, ter popolno in delno improvizacijo. ${ }^{2}$ Danes razumemo, da je improvizacija zmeraj na neki

1 Ferand, Die Improvisation in der Musik.

2 Nav. delo, 9. 
način zamejena. Da bi lahko razumeli določeno improvizacijsko prakso, je ključnega pomena razumevanje vloge improvizacije in konteksta, znotraj katerega improvizacijski dogodek poteka. Značilnost vseh improvizacijskih praks je omejitev, ki jo improvizatorjem predstavlja izvajanje v realnem prostoru in času. ${ }^{3}$ Barry Martin in Kenny Gellrich, ki sta preučevala improvizacijski proces z vidika psihologije, ugotavljata, da poleg omejitve izvajanja v realnem času na izvajalčevo improviziranje vplivajo »notranje « in »zunanje« improvizacijske omejitve. ${ }^{4}$ Kot notranje omejitve razumeta psihološke in fiziološke omejitve izvajalca, kot zunanje omejitve pa opredeljujeta tiste, ki jih določa družbeno-kulturni kontekst. Improvizator se nauči predvideti izzive, ki bi jih določena improvizacijska situacija lahko zahtevala. $^{5}$

Improvizacija je zahtevna: od izvajalca zahteva veliko premišljenosti, načrtovanja, zbranosti, iznajdljivosti in hitre presoje; glasbenik mora znotraj danega improvizacijskega okvirja svoj lastni izraz nenehno prilagajati omejitvam in pravilom, ki mu jih narekujeta improvizacijski žanr in oblika, v iskanju ravnotežja pa mora posvečati pozornost tudi družbenim zakonitostim in raznovrstni spremenljivosti konteksta. S svojim igranjem improvizator izraža tudi lastno glasbeno osebnost, zato se mora, še posebej, če je profesionalni glasbenik, ki se z igranjem preživlja, nujno soočiti z vprašanji, do kolikšne mere bo svojo družbeno identiteto in lastni izraz prilagodil pričakovanjem publike in trenutnim glasbenim tokovom. Tako kot je v današnjem času improvizator vedno vpet v kontekst glasbenega dogodka in v improvizacijsko tradicijo, katere del je, se je tudi profesionalni pianist 19. stoletja pri svojem delu srečeval z vprašanjem, kako se to, kar igra, sklada z glasbeno tradicijo in kako bodo poslušalci njegovo igranje sprejeli. Pričujoča analiza Czernyjeve razprave odgovarja na vprašanje, kaj je moral profesionalni pianist, ki je improviziral v času romantike, razumeti, katera znanja je moral pridobiti in v čem se je moral uriti, da je lahko svoj nastop suvereno izpeljal.

Czernyjeva razprava je zanimiva zato, ker kot pomemben element improvizacijskega znanja ne poudarja le razumevanja glasbene tradicije in obvladovanja glasbeno-tehničnih znanj, temveč tudi upoštevanje družbenih in individualnih vidikov improviziranja. Dosedanje analize Czernyjeve razprave so bile usmerjene predvsem v splošne ter glasbene značilnosti improvizacije tistega časa ali pa so se dotikale specifičnih vidikov improviziranja, kot so na primer značilnosti podajanja improvizacijskega znanja. ${ }^{6} \mathrm{~V}$ pričujočem

3 Kenny in Gellrich, »Improvisation«, 117.

4 Nav. delo, 117.

5 Blum, »Recognizing Improvisation«, 27.

6 Alice Levine Mitchell, ki je pripravila angleški prevod Czernyjeve razprave, je podala splošni uvod $\mathrm{v}$ prakso klavirskega improviziranja in se ni spuščala $\mathrm{v}$ podrobno glasbeno analizo improvizacijskih žanrov. Gl. Mitchell, »Translator's Foreward«, ix-xiv. - Mike De Grace Zachary je Czernyjevo razpravo preučeval z vidika glasbenooblikoslovnih in estetskih značilnosti žanra klavirske fantazije 19. stoletja. Gl. De Grace Zachary, »Style and Structure in Selected Viennese Keyboard Fantasias of the Early Nineteenth Century«, 8-31. - Ulrich Mahlert, ki je pripravil prvi faksimilni izvod Czernyjeve razprave, je svojo analizo osredotočil predvsem na primerjavo posameznih Czernyjevih misli s kritiko razprave, ki jo je podal njegov sodobnik, glasbeni teoretik Gottfried Wilhelm Fink, ter na primerjavo z razpravo Ausführlich theoretisch-practische Anweisung zum Piano-forte Spiel (1828) Johanna Nepomuka Hummla. Gl. Mahlert, »Einführung«, iii-xv. - Aaron Lee Berkowitz je v svojem doktorskem delu razpravo obravnaval 
prispevku so najprej izpostavljene temeljne estetske karakteristike klavirskega improviziranja 19. stoletja, kot jih je razumel Czerny, vendar se analiza osredotoča predvsem na Czernyjev pogled na veščine in vrednote profesionalnih pianistov tistega časa in na njihovo družbeno umeščenost.

\section{Predstavitev zbirke}

Systematische Anleitung zum Fantasieren auf dem Pianoforte op. 200 (1829) ali »Sistematični uvod v improviziranje na klavirju « je delo klavirskega pedagoga Carla Czernyja (1791-1857), ki velja za eno najpomembnejših razprav o klavirski improvizaciji 19. stoletja. Obravnava znanje, ki je potrebno za improviziranje v fantazijskem stilu in ponuja izjemen vpogled v prakso klavirskega improviziranja tistega časa. Razprava vsebuje uvod, v katerem je Czerny podal svoje dojemanje improvizacije, devet poglavij - v vsakem od njih se je posvetil določeni improvizacijski obliki, ter kratek zaključek, kjer je še posebej izpostavil pomen vadbe in praktičnih izkušenj za učenje improviziranja.

Czernyjeva razprava je zanimiva $\mathrm{z}$ mnogih vidikov. V njej je avtor na sistematični način obravnaval tipične improvizacijske oblike svojega časa, ob opisu vsake od oblik pa je izpostavil tudi splošno sprejete konvencije izvajalske prakse. Iz Czernyjevega dela je jasno razvidno, da improviziranje ni bilo le veščina spontanega ornamentiranja fermat in kadenc ter igranja preludijev, temveč samostojna umetniška praksa. Menil je, da je umetnost improviziranja "posebna obveza in glavna prepoznavnost « ${ }^{7}$ klavirskega virtuoza. Svojo razpravo o improvizaciji je namenil profesionalnim pianistom, vendar naj bi jo po njegovem mnenju uporabljali tudi amaterski pianisti, če le imajo dovolj predznanja in izvajalskih sposobnosti.

Sposobnost improviziranja je bilo po Czernyjevem mnenju mogoče razviti z usmerjeno in sistematično vadbo, vendar je avtor predpostavljal, da pianist tako za učenje improviziranja kot tudi skladanja potrebuje troje: prirojeno nadarjenost, ponotranjeno razumevanje harmonije in že izpopolnjeno izvajalsko tehniko. Ponudil je mnogo nasvetov in napotkov, kako naj bi pianist pristopil k vadbi improvizacije, vendar se je kljub vsemu izogibal metodološko jasno zastavljenih tehničnih vaj, ki bi proces učenja improviziranja demistificirale do te mere, da bi improvizatorja začetnika vodile korak za korakom. Improvizator je moral imeti ob študiju njegovega učbenika preiskovalni odnos; Czernyjev pristop k poučevanju improvizacije je namreč temeljil na podajanju splošnih smernic in improvizacijskih modelov, podkrepljenih z mnogimi primeri vzorčnih notiranih improvizacij.

Pianist se je ob preučevanju Czernyjeve razprave lahko seznanil z estetskimi in umetniškimi vidiki improviziranja ter z nasveti, kako se spopadati s praktičnimi težavami, ki vzniknejo pri spontanem igranju pred publiko. Mnogi nasveti in razmišljanja odstirajo pogled v Czernyjevo razumevanje kompleksnosti improvizacijskega procesa. V učbeniku je sistematično predstavil žanre klavirskega improviziranja 19. stoletja. Svojega bralca je postopoma vodil skozi primere raznolikih improvizacijskih oblik do spoznanja,

v kontekstu preučevanja pedagoških strategij za poučevanje improvizacije v različnih improvizacijskih učbenikih 19. stoletja. Gl. Berkowitz, »Cognition in Improvisation«.

7 Czerny, Systematische Anleitung zum Fantasieren auf dem Pianoforte, 2. 
da je improvizacija proces, ki zahteva moč dveh sil: ustvarjalne sile osebnega izraza in sposobnost obvladovanja te ustvarjalne sile v smislu tehnične izurjenosti in razumevanja glasbenega jezika. Za razumevanje napotkov za improviziranje je pianist potreboval kar nekaj predznanja, saj avtor v svojo razpravo ni vključil osnovnih glasbenih znanj in definicij kompozicijskih tehnik, kot so moduliranje, imitiranje ter osnovni principi dela z motivom. Predpostavljal je, da bo njegov bralec vse to že poznal.

\section{Improvizacijske oblike}

Improvizacijske oblike Czernyjeve razprave so po glasbenih značilnostih sledile uveljavljenim kompozicijskim oblikam. V prvih treh poglavjih je avtor obravnaval najpreprostejše improvizacijske oblike: preludije in kratke improvizacijske vložke, kot so kadence in fermate. V nadaljevanju je predstavil improvizacijske oblike, ki funkcijsko niso vezane, temveč predstavljajo samostojne oblike improviziranja. To so: improvizacija na eno temo, improvizacija na več tem, potpuri, variacije, improvizacija v strogem vezanem in fugatnem stilu in capriccio. Te oblike je predstavil kot tretjo kategorijo improviziranja, ki jo je poimenoval »resnična, samostojna fantazijska improvizacija.$^{8} \mathrm{~S}$ temi besedami je avtor nakazal, da je improvizacija avtonomna umetnost, in ne le način spontanega izvajanja. Improvizacijske oblike je bilo mogoče med seboj tudi kombinirati. Vsa poglavja je Czerny oblikoval na podoben način: najprej je bralca seznanil z glasbenimi in oblikoslovnimi značilnostmi posamične oblike, nato pa je predstavil več glasbenih primerov, ki so obravnavano improvizacijsko obliko dodatno pojasnjevali. Nekatere improvizacijske oblike so izvajalcu dopuščale veliko svobode v izbiri glasbenega materiala in vzdušja, medtem ko so druge od improvizatorja zahtevale premišljeno izbiro značaja improvizacije.

Preludiji so zahtevali, da izvajalec improviziranje prilagodi vsebini, vzdušju in glasbenim značilnostim sledeče kompozicije. Še posebej je bilo pomembno, da je izvajalec preludij zaključil v tonaliteti, s katero se je začela naslednja skladba. Glede na oblikoslovne značilnosti je preludije razdelil na krajše, ki jih je improvizator razvil na podlagi kratkega zaporedja akordov, ter na daljše preludije. Slednje je improvizator oblikoval kot samostojni uvod, ki naj bi izkazoval oblikovno skladnost. Vanje naj bi vključil tematsko gradivo sledeče kompozicije in jih zaključil na dominantnem septakordu ustrezne tonalitete. Kot posebno vrsto preludiranja, ki dopušča več izrazne svobode, je Czerny izpostavil recitativu podoben nemenzurirani preludij. Pianista je opozoril, naj pred zahtevnimi skladbami in kadar spremlja druge instrumente, ne improvizira predolgih preludijev.

Improviziranje kadenc in podobnih kratkih improvizacijskih vložkov je po vzdušju, vsebini in glasbenem materialu prav tako moralo slediti značilnostim dane kompozicije. Pravila oblikovanja so zahtevala, da se med potekom kadence ne modulira in da se ob koncu lepo poveže s prvim taktom sledečega dela skladbe. Pianist je pri improviziranju kadence gotovo želel pokazati tudi svojo inventivnost in briljantno tehniko, a je po Czernyjevih

8 Nav. delo, 4. 
svarilih kljub vsemu moral paziti, da njegova improvizacija ne bi bila predolga ali preveč »rapsodična«; ${ }^{9}$ le tako je namreč kadenca lahko ohranila svojo funkcijo in učinkovitost.

Improvizacija na eno temo naj bi bila po Czernyjevem mnenju najtežja oblika samostojnega improviziranja. Zahtevala je, da je pianist svojo improvizacijo zasnoval na podlagi ene same teme, le-to na raznolike načine preoblikoval, izpeljal iz nje različne stavke in jih na smiseln način povezal v enovito improvizacijsko fantazijo. Tematsko razvijanje motivov je bila ključna spretnost; brez nje namreč ni bilo mogoče ustvarjati improvizacijskih fantazij. Czerny je za zgled predstavil kratko temo in nato več načinov njenega preoblikovanja, ki so sovpadali s tipičnimi klavirskimi oblikami. Pianista je opozoril, da za razvijanje določenih oblik ni vsaka tema enako primerna. Spretnost spontanega razvijanja teme je tako zahtevala veliko premišljenosti: izvajalec je moral znati dobro presoditi, katere oblike bodo za izbrano temo najprimernejše in obratno. Czerny je pianistu priporočil, da iz teme vzame zgolj kratek motiv in ga uporabi kot temeljno glasbeno idejo celotne improvizacije. Enostavni motivi bodo po njegovem omogočali več svobode in lažje tematsko razvijanje.

Svobodno improviziranje na več temah je po Czernyjevem mnenju za sproščeno izražanje izvajalčevih čustev in trenutnega počutja najprimernejša improvizacijska oblika. V njej pa se je potrebno izogniti tako povsem naključnim glasbenim vzgibom kot tudi discipliniranosti običajnega komponiranja. Izvajalec lahko tu v eno improvizacijo vplete več različnih tem, po Czernyjevem mnenju pa mora teme premišljeno izbirati, da si po značaju ne bi bile preveč tuje.

Potpuri je izpostavil kot najprimernejšo improvizacijsko obliko, s katero bo pianist najlažje nagovoril raznoliko publiko. Definiral ga je kot »premišljeno in zanimivo kombinacijo tem, ki so pri publiki že priljubljene. $\aleph^{10}$ Pianist se je pri tej obliki s poslušalci lahko sporazumeval tudi tako, da je poznane napeve med seboj nizal in interpretiral na različne načine: »Motive pesmi, katerih besedilo je na splošno poznano, lahko s pomočjo smiselnih kombinacij uredimo ljubko ali pomenljivo. « ${ }^{11}$ Improvizacija je morala biti uravnotežena tako v uporabi kompozicijskih tehnik, kot je na primer izmenjavanje figuracij s pasažami, kot v smislu uravnoteževanja posameznih delov v smiselno celoto.

Variacije naj bi improvizator razvijal na enak način kot tedanji skladatelji. Ključna spretnost, ki jo je moral pianist pri tej improvizacijski obliki obvladati, je bila prepoznavanje in izbiranje primernih tem, ki bodo dopuščale oblikovanje kar najrazličnejših variacij. Po Czernyjevem mnenju so najprimernejše teme »tiste, ki imajo prikupno melodijo, nimajo veliko modulacij, imajo dva enakomerno razdeljena dela in izrazit ritmični profil. 12 $^{12}$ Sposobnost prepoznavanja značilnosti teme in določevanja tiste njene oblike, ki bi bila za improvizacijo najprimernejša, je bila pomembna tudi zato, ker je temo lahko predlagala publika.

Improvizacijo v vezanem in fugatnem načinu je bilo mogoče oblikovati s tremi tehnikami, ki jih je improvizator lahko tudi medsebojno kombiniral: s povezovanjem

\footnotetext{
9 Nav. delo, 4.

${ }^{10}$ Nav. delo, 75.

${ }^{11}$ Nav. delo, 75.

${ }^{12}$ Nav. delo, 94.
} 
zaporedij akordov, s tehniko imitiranja, pri kateri se figure ponavljajo v vseh glasovih, in s strogo imitacijo, kot v fugi.

Cappricio je predstavljen kot najsvobodnejša oblika improviziranja. Vanj je bilo mogoče vplesti raznovrstne glasbene ideje in jih na poljuben način povezovati. Prevladovalo naj bi šaljivo vzdušje. Kompozicij, ki bi ustrezale tej zvrsti, po Czernyjevem mnenju ni veliko; kot primer navaja Beethovnovo Fantazijo v g-molu, op. 77.

Vsako poglavje je Czerny zaključil s seznamom priporočenih kompozicij, ki so improvizatorju lahko služile bodisi kot modeli za improvizacije bodisi kot dodatni primeri za preučevanje razvijanja glasbenega gradiva v raznolikih kompozicijskih oblikah. V seznamu dodatne glasbene literature je Czerny običajno najprej omenil nabor svojih skladb, nato pa je pianista napotil na glasbena dela skladateljev, kot so J. S. Bach, W. A. Mozart, L. van Beethoven, ter na dela njegovih sodobnikov, klavirskih improvizatorjev, kot so bili I. Moscheles, J. N. Hummel, F. Kalkbrenner ter F. Ries.

\title{
Estetika improviziranja
}

Vpogled v razpravo pokaže, da improviziranje ni bilo prosto poigravanje z glasbenimi mislimi, kot bi si lahko predstavljali improviziranje v »romantičnem« 19. stoletju, temveč je temeljilo na »točno določenih pravilih. «13 Pianist je moral svoje improvizacije premišljeno voditi in jih urediti v improvizacijsko kompozicijo, v kateri so tudi poslušalci lahko zaznali umetnikovo namero, prepoznali smisel ter organizacijo njegove invencije. Czernyjevo dojemanje improvizacije ne zajema le spontanega izražanja, temveč tudi sposobnost, da izvajalec svoje glasbene misli hkrati ureja v koherentno celoto. Takole zapiše Czerny:

\begin{abstract}
Kadar je učeči se glasbenik sposoben izvajati ideje, ki v trenutku nastanka izvirajo iz njegove lastne inventivnosti, inspiracije ali vzdušja, in jih je sposoben ne le zaigrati, ampak sočasno povezovati tako, da bo lahko skladnost poslušalcu dala občutek dejanske kompozicije, imenujemo to fantaziranje (improviziranje, ekstemporiranje). - Nadarjenost za improvizacijo in umetnost improviziranja zatorej pomeni sposobnost, da med samim igranjem, brez posebne neposredne predpriprave, vsako izvirno ali pa tudi sposojeno idejo poljubno razvijemo v neke vrste glasbeno kompozicijo, katere oblika je sicer veliko bolj svobodna kot zapisano delo, a mora biti kljub temu oblikovana v urejeno celoto, $\mathrm{v}$ kolikor je potrebno, da se ohranja razumljivost in zanimivost. ${ }^{14}$
\end{abstract}

V Czernyjevi razpravi je ključnega pomena spoznanje, da pianist v izražanju svojih misli ne more biti popolnoma svoboden; pri improviziranju se mora ozirati na splošno sprejete zahteve izvajalske prakse, svoje improvizacijske odločitve pa mora znati uskladiti z zahtevami, ki jih narekuje priložnost glasbenega dogodka. Značilnosti izurjenega improviziranja, kot jih nakaže Czerny, so jasno izražanje glasbenih misli in spretnost premišljenega obdelovanja glasbenega gradiva.

Publiko 19. stoletja je gotovo pritegnilo razkazovanje izvajalskih spretnosti klavirskih virtuozov, vendar pa Czernyjeva razprava nakazuje, da so bila tehnična znanja, četudi

${ }^{13}$ Nav. delo, 3.

${ }^{14}$ Nav. delo, 3. 
nepogrešljiva in izredno pomembna, zgolj predpogoj - smisel improviziranja se je kazal v drugih presežkih. Sledeče Czernyjevo razmišljanje osvetljuje njegovo razumevanje estetike improviziranja:

Če lahko dobro komponirano delo primerjamo s kvalitetno arhitektonsko zgradbo, v kateri mora prevladovati simetrija, potem je dobra fantazija podobna lepemu angleškemu vrtu, ki se le dozdeva neurejen, vendar je poln presenečenj in izdelan racionalno, torej smiselno in po načrtu. ${ }^{15}$

Iz odlomka je razvidno, da je kvaliteto improviziranja avtor prepoznaval v ravnotežju izvajalčeve invencije in premišljene organizacije. Bolj kot izvirnost je Czerny poudarjal premišljenost, obvladovanje, načrtnost in umerjenost. Iz njegove razprave je jasno razvidno, da je improviziranje dojemal ne le kot veščino, temveč kot samostojno vejo umetnosti, ki se je s kompozicijo povezovala predvsem v oblikoslovnem smislu.

Pianistovo improviziranje je temeljilo na poznavanju sočasne kompozicijske prakse in tradicije, vendar se je od izvajanja kompozicij razlikovalo v estetskem smislu. Improvizacija je morala poslušalcem vedno dati občutek spontanosti, ki ga po Czernyjevem mnenju V »komponiranih delih (četudi so zamišljena kot fantazije) ni mogoče najti. « ${ }^{16}$ Občutek spontanosti je tako predstavljal eno od ključnih improvizacijsko-izvajalskih vrednot. Poslušalec nikakor ni smel dobiti občutka, da je izvajalec improvizacijo vnaprej zvadil, oziroma da jo v resnici igra po spominu. V poglavju o preludijih je Czerny pianista posvaril s temi besedami: »Kajti nič ni bolj moteče, kot občutek, da se je izvajalec preludij [do podrobnosti] naučil. ${ }^{17}$

Czerny je prepoznaval kvalitete dobrega klavirskega improvizatorja tako v tehnični izurjenosti in njegovi nadarjenosti za umetniško invencijo kot tudi v občutljivosti, da svojo improvizacijo kroji glede na pričakovanja svojih poslušalcev. Ob dejstvu, da improvizator ni imel časa, da bi svojo invencijo izpilil in da bi svoje odločitve lahko dobro pretehtal, so se improvizacije od izvedbe komponiranih del razlikovale predvsem v odnosu izvajalca do poslušalcev. Pri improvizaciji je občinstvo lahko zavzelo bolj aktivno vlogo. Naslednji odlomek, v katerem je avtor izpostavil povezavo med govorništvom in improviziranjem, nadalje pojasni njegovo razumevanje koncepta glasbene improvizacije kot veščine, ki zahteva izurjenost v obvladovanju jezika, čuječnost in zbranost ter domišljeno invencijo, premišljeno vpeto v vsakič drugačne okoliščine improvizacijskega dogodka:

Prav tako, kot se govornik s prefinjenostjo, gracioznostjo, jasnostjo in izbranimi podobami ter cvetočim jezikom izogiba pustosti in dolgočasnosti, mora tudi glasbeni izvajalec $\mathrm{z}$ lepim in okusnim izražanjem, s čuječnostjo, z upoštevanjem poslušalčevih sposobnosti razumevanja, z eleganco in primernim okraševanjem doseči posebno lepoto igranja.

Sicer pa drži, da je improviziranje, še posebej ob velikem prirojenem talentu in mnogih veščinah, pogosto skoraj nezavedno in zasanjano igranje prstov; takšno je še toliko boljše, saj tudi govornik ne razmišlja vnaprej o vsaki besedi in frazi. Vendar pa mora biti izvajalec vedno zbran (še posebej, kadar razvija že dano temo), držati se mora

\footnotetext{
${ }^{15}$ Nav. delo, 3.

${ }^{16}$ Nav. delo, 15.

${ }^{17}$ Nav. delo, 15.
} 
zastavljenega načrta, ne sme se prepustiti niti nerazumljivi rapsodični suhosti niti preveč razkošnemu, širokemu razvijanju. ${ }^{18}$

Kakor je Czerny nakazal v primerjavi improvizatorja z govornikom, je moral pianist med igranjem ohranjati celostno idejo svoje improvizacije in se zavedati njene vpetosti v kontekst glasbenega dogodka. Iz njegovih napotkov je jasno razvidno, da improviziranje nikoli ne bi smelo biti prazno tehnično bahanje ali povsem nekontrolirano, zasanjano pohajanje. Improvizator se je lahko prepustil danemu trenutku, vendar je moral vselej ohranjati nadzor nad situacijo in razvijati svoje igranje tako, da je bilo primerno načrtu izbrane improvizacijske oblike. Da se je lahko med improviziranjem suvereno odzival na notranje in zunanje impulze, da je bilo njegovo improviziranje zanimivo poslušalcem in ustrezno glede na vnaprej zastavljeni improvizacijski okvir, je moral razviti sposobnosti izredne zbranosti in čuječnosti. Improvizacijski modeli so resda predstavljali pomembno vodilo, improvizator pa se je moral pri igranju ozirati in odzvati na specifični kontekst. Czerny je pianista podučil, da naj ob osredotočanju na svoje lastno igranje pozorno sledi tudi vzdušju občinstva, opazuje odzive in skuša biti vselej v pripravljenosti. Zapisal je:

Glede na celoto morajo izvajalca voditi prečiščen okus, izostren občutek za to, kaj sodi skupaj, zavest, da igra občinstvu, in še posebej občutljivost, ki mu pomaga zaznati, ali in kako hitro je potrebno $\mathrm{z}$ novim motivom ponovno vzbuditi pozornost poslušalcev, zato da v njih nikoli ne bi pustil zamreti zanimanja. Slednje lahko pridobimo le s širokimi izkušnjami in prakso. ${ }^{19}$

Glede na raven glasbenega razumevanja svojih poslušalcev in še posebej glede na njihovo pozornost je improvizator torej moral znati oceniti, koliko improvizacijske svobode si v določenem trenutku lahko privošči. Prepoznati je moral trenutke pojenjajočega zanimanja ter se $\mathrm{v}$ takih primerih oprijeti preverjenih improvizacijskih rešitev, kot je uporaba priljubljene melodije ali pa vpeljava nepričakovanega glasbenega elementa. Czerny je pianista opozoril, da mora biti ob tem pozoren na meje primernega in slediti tehnikam izpeljevanja, ustreznim dani improvizacijski obliki. Pomembna sposobnost, ki jo je moral razviti, je bila prepoznati improvizacijski kontekst in razviti občutek za to, kaj je v določeni situaciji primerno.

\section{Vadba improvizacije}

Poigravanje s poslušalčevimi pričakovanji in sposobnost vzdrževanja želenega vzdušja je od improvizatorja zahtevala ne le tehnično izurjenost in prilagodljivost, temveč tudi določeno mero družbene inteligence, da je avditorij uspel pritegniti. Nekatere improvizacijske odločitve je izvajalec sprejel že pred začetkom glasbenega dogodka, druge pa je prepustil okoliščinam izvajanja. Pianist je poznal program svojega nastopa, zato je lahko improvizacije pripravil in začrtal v skladu s skladbami, ki jih je igral. Pred samo izvedbo

${ }^{18}$ Nav. delo, 36 .

${ }^{19}$ Nav. delo, 75. 
je moral vedeti, kaj želi s svojo improvizacijo sporočiti, oziroma kakšen učinek želi s svojo improvizacijo pri zbranem občinstvu doseči: jih bodisi zabavati, pokazati »prefinjenost svojih čustev $\ll^{20}$ ali pa jih predvsem navdušiti s svojo virtuoznostjo. Premisliti je moral tudi to, kako bo svojo namero izpeljal glede na improvizacijski okvir, ki si ga je izbral in zastavil glede na okoliščine glasbenega dogodka. Še preden je zaigral eno samo noto, si je zamislil improvizacijski načrt in se odločil za najprimernejšo improvizacijsko obliko. Določil jo je glede na značilnost publike, glede na primernost glasbenemu dogodku, glede na instrument, na katerega je igral, in glede na čas, ki ga je imel na voljo. Za svoje improvizacije si je moral tako vnaprej pripraviti vsaj okvirno izhodišče, kot so na primer teme ali zaporedja akordov in morebitni modulacijski načrti.

V estetskem smislu je bilo zelo pomembno, da je improvizacija ohranjala občutek naravnosti in spontanosti, zato ni presenetljivo, da je Czerny ravno pri obravnavi preludijev še posebej poudarjal, da mora igranje zveneti neprisiljeno in lahkotno. Improvizacijski preludiji so namreč omogočali več vnaprejšnje priprave, saj je izvajalec skladbo, ki naj bi jo preludij uvajal, poznal in se je lahko nanj ustrezno pripravil.

Improvizatorji lahko z virtuoznim nizanjem glasbenih misli vzbudijo občutek popolne spontanosti glasbene invencije, vendar morajo vsled tako postavljenemu cilju $\mathrm{k}$ improviziranju pristopati analitično, sistematično in zelo premišljeno. $Z$ vsakodnevno vadbo morajo po Czernyjevem mnenju naključne glasbene vzgibe in premišljene glasbene oblike vpenjati v domiselne in koherentne glasbene celote.

Improvizatorju so kompozicijske oblike predstavljale okvirni skelet, ki mu je pomagal glasbene misli oblikovati v smiselno celoto. Czernyjevi glasbeni primeri so pogosto zastavljeni tako, da najprej prikažejo izhodiščno glasbeno idejo, nato pa iz nje izpeljane celotne improvizacije. Iz glasbenih primerov, prav tako pa tudi iz razlag je razvidno, da je Czerny svoje improvizacije gradil povečini s pomočjo tematskega razvijanja glasbenega gradiva in s premišljenim oblikovanjem le-tega $v$ oblikovno zaključene improvizacijske kompozicije. V umetnosti improviziranja naj bi se zatorej pianist začel izpopolnjevati šele, ko je popolnoma obvladal tehniko izvajanja in pa pravilno razvijanje glasbenega gradiva. Vadba izpeljevanja teme in delo z motivom sta se zdela Czernyju zelo pomembna. Menil je, da bi moral pianist temu posvetiti veliko pozornosti in vaditi tako, da poljubne raznovrstne motive izpeljuje $\mathrm{v}$ vseh obravnavanih oblikah. Improvizator je moral biti izurjen $v$ raznolikem razvijanju glasbenega gradiva, da bi z zanimivim pristopom pritegnil svoje poslušalce. Po Czernyjevih priporočilih je moral pianist vztrajati pri vsakodnevni disciplinirani vadbi in se venomer izpopolnjevati v različnih improvizacijskih izzivih. Pianistu je svetoval, naj pred vsako skladbo, ki jo obravnava ali igra, vedno improvizira preludij, pri tem pa naj skuša uporabiti vse možne oblike variiranja. Le raznovrstna vadba improviziranja je lahko pianistu omogočila razvoj potrebnih spretnosti in s tem močnega orodja, ki mu je omogočalo, da se sooči s katerim koli glasbenim gradivom, situacijo in kontekstom.

Improvizatorjeva inventivnost in domišlija sta bili odvisni od njegovega trenutnega počutja in sposobnosti, da se prepusti spontanosti vselej drugačnih okoliščin glasbenega dogodka, zato je moral improvizator vedno imeti pripravljene rešitve za morebitne težave.

${ }^{20}$ Nav. delo, 22. 
Czerny je opozarjal, da bi moral tudi izurjen pianist, ki se je pri igranju sposoben prepustiti svojim občutkom in igrati tako sproščeno, kot da bi mu melodije same »tekle pod prsti«, kljub vsemu v mislih vedno nositi nabor nadomestnih glasbenih idej in tem zato, da bi se izognil nepotrebnim zadregam, do katerih bi lahko prišlo bodisi zaradi pomanjkanja koncentracije bodisi zaradi slabega razpoloženja, treme ali »uničujočega strahu, da bi dolgočasil občinstvo. ${ }^{21}$ Pred nastopom je lahko pripravil nabor pri občinstvu že priljubljenih glasbenih tem. Gotovo je bila takšna priprava še posebej pomembna v primerih, ko je igral pred novo publiko, saj je tako lažje vzpostavil stik s poslušalci. Czerny je pianista spodbudil, da zavestno oblikuje svoje improvizacijsko besedišče in ponotranji glasbene odlomke, ki so mu všeč:

Kot mora govornik združevati splošno načitanost in osnovna znanja z vseh področij svoje vede, je prav tako dolžnost pianista, da se poleg učenja osnovnih principov harmonije seznani tudi z vsemi dobrimi in velikimi deli glasbenih mojstrov vseh obdobij, ter da si iz te literature vtisne v spomin širok nabor zanimivih idej; prav tako mora imeti na razpolago tudi trenutne glasbene novitete, priljubljene motive iz oper, napevov itd. ${ }^{22}$

Profesionalni pianist se je moral naučiti predvideti raznolike umetniške izzive, ki so zahtevali domišljene rešitve ne samo na tehnični ravni, temveč tudi z raznimi vnaprej pripravljenimi posebnimi učinki, kot je na primer pomenljiva uporaba dobro poznanega glasbenega motiva ali sočasno prepletanje dveh tem.

\section{Zaključek}

Analiza Czernyjevih misli razkriva, kako se je klavirski improvizator 19. stoletja lahko približal pričakovanjem svoje publike in do kolikšne mere ter na kateri način se je lahko oddaljil od konvencij ustaljenih glasbenih oblik. Pri opredeljevanju osnovnih improvizacijskih znanj, kot jih razume Czerny, je mogoče prepoznati tri pomembne sestavine improviziranja: tehnična izurjenost, s katero je improvizator pokazal virtuozno stran improviziranja, estetski vidik oblikovanja improvizacij v skladu s kompozicijsko tradicijo, ter družbena inteligenca, sposobnost komuniciranja s publiko. Izredno pomembno vlogo je imelo tehnično brezhibno obvladovanje instrumenta. Le tehnično izurjen improvizator, ki je imel veliko improvizacijskih izkušenj, se je v svojih ustvarjalnih vzgibih lahko predal trenutku ter »prepustil prosto pot svoji domišljiji . $^{23}$

Czerny prepoznava poznavanje glasbene tradicije in temeljito seznanjenost z deli velikih skladateljev kot pomemben del improvizacijskega znanja. Suvereno in pravilno izražanje z glasbenim jezikom je bilo improvizatorjevo osnovno orodje. Dobro poznavanje kompozicijske prakse je bilo pomembno tako s stališča poznavanja tradicije kot tudi zato,

\footnotetext{
${ }^{21}$ Nav. delo, 75.

${ }^{22} \mathrm{Nav}$. delo, 36.

${ }^{23}$ Nav. delo, 63.
} 
da je improvizator ponotranjil glasbeni jezik, »razvil svojo domišljijo in bistroumnost «24 in izostril občutek za estetiko.

Czernyjevo besedilo nakazuje, da je bila ena od bistvenih improvizatorjevih nalog prevzemanje odgovornosti za lastno občinstvo, vendar so ti vidiki improvizacijske prakse težko ulovljivi in ubesedeljivi. Avtor je svoje delo zaključil z mislijo, da znanje samo po sebi ne bo pripeljalo do spretnega improviziranja in da se bo improvizator kalil predvsem s praktičnimi izkušnjami, tako, da bo improviziral pred poslušalci.

Profesionalni pianist 19. stoletja je svoj osebni improvizacijski izraz lahko razvijal le v presečišču zahtev tradicije, pričakovanj publike in svojih lastnih umetniških hotenj. Vsa ta spoznanja so mu predstavljala osnovo, ki ga je lahko pripeljala do tiste stopnje samostojnosti, ko si je lahko popolnoma zaupal in pri improviziranju odločno sprejemal lastne umetniške odločitve. Svoboda, spontanost in neposredno izražanje čustev je tisto, kar dela improvizacijsko igro privlačno in kar jo ločuje od izvajanja kompozicij; vendar je improvizator svobodo izražanja lahko izkoristil šele potem, ko se je dodobra seznanil z vsemi omenjenimi ključnimi vidiki improviziranja.

\section{Uporabljena literatura}

Berkowitz, Aaron Lee. »Cognition in Improvisation: The Art and Science of Spontaneous Musical Performance.« Dokt. dis., Harvard University, 2009.

Blum, Stephen. »Recognizing Improvisation«. V: In the Course of Performance: Studies in the World of Musical Improvisation, ur. Bruno Nettl in Melinda Russell, 27-45. Chicago: University of Chicago Press, 1998.

Czerny, Carl. Systematische Anleitung zum Fantasieren auf dem Pianoforte, Op. 200. Dunaj: Diabelli \& Cappi, 1829. (Dostopno na spletu.)

--_-_- Systematische Anleitung zum Fantasieren auf dem Pianoforte, Op. 200. Ur. Ulrich Mahlert. Wiesbaden: Breitkopf \& Härtel, 1993.

De Grace Zachary, Mike. »Style and Structure in Selected Viennese Keyboard Fantasias of the Early Nineteenth Century«. Dokt. dis., American Conservatory of Music, 1991.

Ferand, Ernst Thomas. Die Improvisation in der Musik. Zürich: Rhein-Verl., 1938.

Kenny, Barry J., in Martin Gellrich. »Improvisation«. V: The Science \& Psychology of Music Performance: Creative Strategies for Teaching and Learning, ur. Richard Parncutt in Gary McPherson, 117-134. Oxford: Oxford University Press, 2002.

Mahlert, Ulrich. »Einführung«. V: Carl Czerny, Systematische Anleitung Zum Fantasieren Auf Dem Pianoforte, Op. 200, ur. Ulrich Mahlert, iii-xv. Wiesbaden: Breitkopf \& Härtel, 1993.

Mitchell, Allice L. »Translator’s Foreward«. V: Carl Czerny, A systematic introduction to improvisation on the pianoforte, opus 200, prevedla in uredila Allice L. Mitchell, ix-xiv. New York: Longman, 1983.

\footnotetext{
${ }^{24}$ Nav. delo, 99.
} 


\section{PIANO IMPROVISATION PRACTICE ACCORDING TO SYSTEMATISCHE ANLEITUNG ZUM FANTASIEREN AUF DEM PIANOFORTE BY CARL CZERNY}

\section{Summary}

Just as today's improvising musicians are always bound to the context of the music event and to the rules of the improvising tradition, the $19^{\text {th }}$ century professional pianist was similarly faced with a question, in what ways will his playing meet the expected norms of the tradition and the expectations of his audience. My research interest in Czerny's treatise Systematische Anleitung zum Fantasieren auf dem Pianoforte, Op. 200 is centered on answering a question, what kind of knowledge the professional pianist had to attain and what he had to understand, in order to give a skilful public performance. In order to become familiar with Czerny's treatise and his improvisation pedagogy the introducory part of the paper contains an overview of improvisatory styles and their characteristics, which is followed by a discussion of the characteristics of Czerny's understanding of aesthetics of $19^{\text {th }}$ century keyboard improvisation. The analysis is focused on those Czerny's thoughts that illuminate the values and skills of professional pianist of that time and on the meaning of his social establishment. The examination of improvisational process as it is presented in Czerny's treatise showed, that the key aspects of $19^{\text {th }}$ century piano improvising were technical proficiency and virtuosity, the aesthetic side of forming improvisations in keeping with compositional tradition, and social intelligence, needed to be able to communicate and connect with the audience. The value of improvised performances was seen in spontaneity and music imagination, however, the improvising had to be tied up to coherent and thoughtfully organized improvisation composition. The improvisational genres were tightly connected to the heritage of compositional tradition. The most important musician's skills were the ability to allow his musical imagination to lead its fingers, to conform to the chosen improvisational genre and to simultaneously shape the improvisation according to the always changing context. In order to respond to his audience, to capture their attention and notice the level of their comprehension, the improviser had to maintain his alertness and awareness and develop his own toolbox of solutions for different improvisational situations, such as an improvisational vocabulary of various interesting musical ideas. Czerny believed that improvisational knowledge itself was insufficient; the improviser had to attain many experiences in practical improvising before the audience. Czerny's treatise is clear in conveying that improvisational freedom and direct expression of feelings is what makes improvisation attractive, and what distinguishes it from performance of written compositions. Nevertheless, the improviser was able to demonstrate his freedom only when he understood the technical, musical and social aspects of improvising. 